\title{
CRÍTICA A LA LEY GENERAL DE COMUNICACIÓN SOCIAL
}

CRItic to the Government Communication ACT

JAIME FERNANDO CÁRDENAS GRACIA ${ }^{1}$

Resumen: La Ley General de Comunicación Social publicada el día 11 de mayo de 2018 en el Diario Oficial de la Federación es un ordenamiento jurídico que no satisface las exigencias constitucionales de la publicidad oficial previstas en el párrafo octavo del artículo 134 de norma fundamental. En este artículo describimos los contenidos de la ley y exponemos las razones que se esgrimen para que la Ley sea declarada inconstitucional por la Suprema Corte de Justicia de la Nación.

Palabras clave: Publicidad oficial, pluralismo, neutralidad.

Abstract: The Government Communication Act, which was published in the Diario Oficial de la Federacion on may 11 th 2018, is not in accordance to the parameters stipulated in 8th paragraph of the 134th constitutional article. In this paper we explain the contents of this act and why it should be ruled unconstitutional by the Supreme Court of Justice.

KEYWORDS: Official Advertisement, Pluralism, Neutrality.

SUMARIO: I. Introducción; II. La dictadura mediática; III. El derecho comparado de acceso a la información y de la publicidad gubernamental; IV. La publicidad gubernamental en México antes de la Ley vigente; V. Descripción de la Ley General de Comunicación Social; VI. La acción de inconstitucionalidad de la minoría senatorial presentada en contra de la Ley General de Comunicación Social; VII. La acción de inconstitucionalidad de la Comisión Nacional de Derechos Humanos; VIII. Conclusiones; y, IX. Fuentes.

1 Investigador Titular C y PRIDE D del Instituto de Investigaciones Jurídicas de la UNAM, Nivel III del Sistema Nacional de Investigadores de CONACYT, y profesor de la División de Estudios de Postgrado de la Facultad de Derecho de la máxima casa de estudios.<jaicardenas@aol.com>. ORCID: https://orcid. org/0000-0001-7566-2429

Fecha de recepción: 7 de febrero 2019; fecha de aprobación: 17 de mayo de 2019. 


\section{INTRODUCCIÓN}

T $\int \begin{aligned} & \text { emos vivido en México, como lo demostraremos, en una } \\ & \text { dictadura mediática: los medios impresos y electrónicos } \\ & \text { reproducen los puntos de vista de los gobiernos en turno }\end{aligned}$ y de los sectores dominantes-hegemónicos, y no existe ningún pluralismo de medios ni en los medios.

La bibliografía nacional en esta materia es muy limitada y se ha referido, con algunas excepciones, sobre todo a la propaganda gubernamental en las campañas electorales. ${ }^{1}$ Es necesario contar con mayores estudios sobre la publicidad oficial en periodos no electorales.

1 Apreza Salgado, Socorro, "La regulación de la publicidad oficial y las medidas anticoncentración de medios de comunicación: otro nudo gordiano del pluralismo informativo en México", Revista de la Facultad de Derecho de México, México, vol. 60, número 254, 2010; Baños, Marco Antonio y Carriedo, Luis Miguel, "Distorsiones de la propaganda política", Revista Justicia Electoral, México, Vol. 1, número 5, 2010; Corral Jurado, Javier, "Propaganda gubernamental y artículo 134 constitucional" en Ackerman Rose, John Mill (coordinador), Elecciones 2012: en busca de la equidad y legalidad, México, UNAM-Instituto de Investigaciones Jurídicas de la UNAM y Senado de la República, 2011; Desiree Salgado, Eneida y Seraphim Makarausky, Camila, "Propaganda electoral, publicidad gubernamental y encuestas electorales: un análisis del modelo mexicano desde una mirada brasileña", Sufragio. Revista Especializada en Derecho Electoral, México, número 12, 2014; Guevara Montemayor, Alberto, "Suspensión de propaganda gubernamental y derecho de acceso a la información pública: hacia un punto de equilibrio en México", en Revista Estudios en Derecho a la Información, México, número 1, enero-junio de 2016; López Guerra, Luis, y otros, Derecho constitucional. El ordenamiento constitucional. Derechos y deberes de los ciudadanos, Volumen I, Valencia, 2018; Magistrados de la Sala Superior del TEPJF, Propaganda gubernamental. Excepciones durante un periodo de campaña. Expediente SUP-RAP-54/2012 y acumulados, México, Tribunal Electoral del Poder Judicial de la Federación, 2014; Marván Laborde, María, "La propaganda gubernamental: un exceso", Revista Hechos y Derechos del Instituto de Investigaciones Jurídicas de la UNAM, México, número 39, mayo-junio, 2017, disponible en: <https://bit.ly/2RDOoXm>; Salazar Rebolledo, María Grisel, "Resistiendo el clientelismo. Publicidad gubernamental y subsistencia de la prensa crítica", Colombia Internacional, número 95, Colombia, 2018, disponible en: <https://bit.ly/2TYcicr>; Trejo Delarbre, Raúl, "Información y medios en la Constitución de la Ciudad de México", en Configuraciones. 
El principio de neutralidad mediática en materia de publicidad oficial es inexistente en nuestro país. Esta publicidad, que es más bien propaganda, siempre ha servido para apuntalar a los gobiernos en turno, fundamentalmente a los titulares del poder ejecutivo de nuestro país.

Durante la historia reciente de nuestro país, el poder mediático aliado con el poder político ha impuesto a grandes sectores de nuestra sociedad sus concepciones de la realidad. Esas nociones han sido la expresión de una hegemonía ideológica en donde la verdad social, económica e histórica es construida para satisfacer los intereses de los grupos dominantes y en el poder.

En el contexto de la dictadura mediática se aprobó la ley general de comunicación social que no resuelve el uso discrecional y manipulado de los recursos públicos empleados para la publicidad oficial. En este artículo exponemos las principales críticas a la Ley que entró en vigor el 1 de enero de 2019. Contra la ley se promovieron diversas acciones de inconstitucionalidad. Aquí damos cuenta de dos de ellas.

La Suprema Corte de Justicia de la Nación tiene en sus manos la posibilidad de declarar la inconstitucionalidad general de la ley, a efecto de que el Congreso de la Unión apruebe una que sí satisfaga los parámetros constitucionales y los estándares internacionales en la materia.

\section{LA DICTAdURA MEdí́tica}

En México es necesario que las autoridades, pero también a los medios de comunicación -con fundamento en el artículo 6 de la

Aportes al debate constituyente de Ciudad de México, Revisa de la Fundación Pereyra y del Instituto de estudios para la transición democrática, número, 41, mayo-agosto de 2016; y, Villafranco Robles, Citlali, "Campañas electorales en el límite de la ley. El caso de la propaganda gubernamental del Partido Verde Ecologista de México", Revista Justicia Electoral, Vol. 1, número 17, enero-junio, 2016. 
Constitución y en el artículo 13 de la Convención Americana de Derechos Humanos- cumplan cabalmente con el derecho a la información. Sostenemos que ha existido una dictadura mediática al no garantizarse cabalmente el derecho a la información, por lo siguiente:

1. El derecho a la información consiste, no sólo en el acceso a la información de las posiciones del gobierno y de los grupos dominantes en la sociedad, sino que entraña el acceso a la información de todos los puntos de vista de los sectores relevantes de la nación;

2. En México no tenemos pluralismo de los medios -que exista una gran cantidad de medios que difundan versiones diversas sobre los problemas nacionales- porque a pesar de las últimas reformas en materia de telecomunicaciones y radiodifusión el espacio radioeléctrico sigue concentrado en unas cuantas empresas. Existe un oligopolio mediático.

3. No hay pluralismo en los medios -que se garantice el derecho de los periodistas de cada medio a disentir de la línea editorial o toral del respectivo medio- sin temor a ser despedidos o sancionados por la empresa (cláusula de conciencia a favor del periodista trabajador).

4. El acceso a las concesiones sobre el espacio radioeléctrico ha obedecido a criterios políticos para favorecer a ciertas y pocas empresas y no a pautas basadas en la imparcialidad.

5. El derecho a recibir información plural y veraz no está suficientemente garantizado. Los medios mexicanos suelen distorsionar la realidad a favor de los grupos dominantes.

6. Los integrantes de la sociedad no contamos con el derecho a participar en la discusión de los asuntos públicos en los medios. Ese derecho es sólo de los representantes de los grupos en el poder político o económico. 
7. El derecho a la información se ha constituido muchas veces en una forma de propaganda a favor del gobierno en turno en contra de lo previsto en el párrafo octavo del artículo 134 de la Constitución.

8. No contamos con un órgano constitucional efectivamente independiente, que no derive de las cuotas de poder de los partidos, y que garantice el derecho a la información. El Instituto Federal de Telecomunicaciones es expresión de los partidos dominantes en el poder legislativo, los que designan a sus titulares.

9. El sistema jurídico y político nacional a través de los medios, especialmente con motivo de la aprobación de las reformas estructurales del anterior gobierno, ha reproducido los puntos de vista de los gobiernos en turno y de los sectores dominantes-hegemónicos sin dar oportunidad en igualdad de circunstancias a la expresión de las expresiones disidentes y alternativas. ${ }^{2}$

10. Los operadores políticos y mediáticos del gobierno de manera dolosa, con alevosía, premeditación y ventaja, avasallan o pretenden avasallar a sectores sociales mayoritarios. Imponen las supuestas reglas del debate en su beneficio para que sólo una voz y una posición prevalezca -la del gobierno o la de los poderes fácticos- y, de manera intencionada presentan esa interpretación de la realidad como la realidad misma. ${ }^{3}$ El objetivo de esa artimaña es que la sociedad no se entere de las terribles consecuencias fiscales,

2 La relación medios-poder-sociedad es determinante en la definición de las características de un régimen político. Ver: Montabes Pereira, Juan, La prensa del Estado durante la transición política española, Madrid, siglo XXI editores y Centro de Investigaciones Sociológicas, 1989.

3 Esteinou Madrid, Javier y Alva de la Selva, Alma Rosa (coordinadores), La "Ley Televisa" y la lucha por el poder en México, México, Universidad Autónoma Metropolitana, 2009. 
políticas, económicas y de pérdida de soberanía nacional que acarrean muchas de las decisiones gubernamentales hegemónicas. Su propósito es que la sociedad desconozca cómo se maximizan las ganancias de los sectores privados privilegiados con los recursos públicos de todos los mexicanos. El fin último de los operadores mediáticos del gobierno es que los motivos y los fines de las políticas del gobierno se desconozcan por las mayorías, pues las decisiones del gobierno incrementarán la riqueza del 1\% de la población en detrimento del 99\% de la población restante. ${ }^{4}$ Por eso, el gobierno con la complicidad de los medios impulsa las reformas jurídicas en la vaciedad de la inexistente discusión legislativa, atropellan la deliberación y minimizan las voces, posiciones y opiniones alternativas.

Esos operadores mediáticos del gobierno desconocen lo que significa la democracia. Piensan que ésta consiste sólo en la aprobación de las leyes por mayorías legislativas ad hoc. Se han olvidado de leer a Tocqueville ${ }^{5}$ y a John Stuart Mill ${ }^{6}$ en relación con el concepto de tiranía de la mayoría legislativa o gubernamental. Ésta se produce cuando la "mayoría" legislativa, al adoptar las decisiones, violenta los derechos de millones de excluidos por el sistema. Tampoco han leído a Sartori que explica, que en el contexto constitucional contemporáneo, tiranía de la mayoría significa violar, legislando o gobernando por unos cuantos que se encuentran divorciados de la sociedad, los derechos humanos de millones. ${ }^{7}$ No puede existir de-

4 Stiglitz, Joseph, El precio de la desigualdad. El 1\% de la población tiene lo que el 99\% necesita, traducción de Alejandro Pradera, México, Taurus-Prisa Ediciones, 2012, p. 249.

5 Tocqueville, Alexis de, La democracia en América, México, Fondo de Cultura Económica, 1957.

6 Stuart Mill, John, Sobre la libertad, Madrid, Alianza editorial, 2017.

7 Sartori, Giovanni, ¿Qué es la democracia?, Madrid, Taurus, 2007. 
mocracia sin que los diversos y plurales sectores de la sociedad, sus voces y posiciones alternativas, tengan en el debate público las mismas oportunidades de exposición y de conocimiento que las voces y posiciones de los que gobiernan. Si ese principio no se garantiza, no hay democracia, lo que existe es la dictadura mediática.

\section{EL DERECHO COMPARADO DE ACCESO A LA INFORMACIÓN Y DE LA PUBLICIDAD GUBERNAMENTAL}

Es común señalar que los derechos a la libertad de expresión y a la información son derechos preferentes frente a otros derechos humanos y principios. ${ }^{8}$ Sin embargo, esos derechos están sometidos a limitaciones y la salvaguarda de la equidad en la materia está ausente. En particular en los procesos electorales, pero también en la relación ordinaria entre el gobierno y la oposición. El derecho comparado así lo advierte.

Temas que son cada vez más importantes en esta materia son el de la neutralidad de los medios y el del pluralismo de los medios de comunicación. Lo que se pretende es lograr la igualdad de armas entre los contendientes en un proceso electoral, es decir, la equidad, pero también para satisfacerla durante periodos inter electorales entre el gobierno y la oposición. Se llega a manifestar que para obtener la igualdad de armas los medios de comunicación además de plurales deben garantizar condiciones de igualdad y neutralidad entre los partidos y candidatos y en los periodos ordinarios entre el gobierno y la oposición.

La ley Orgánica 2/2011 de España, de 28 de enero de ese año, determina en su artículo 66 algo muy relevante para nuestro análisis. Dice así el precepto:

Artículo 66. Garantía de pluralismo político y social.

8 Faúndez Ledesma, Héctor, Los límites de la libertad de expresión, México, UNAM, 2004 p. 17. 
El respeto al pluralismo político y social, así como a la igualdad, proporcionalidad y neutralidad informativa en la programación de los medios de comunicación de titularidad pública en periodo electoral, serán garantizados por la organización de dichos medios y su control previstos en las Leyes. Las decisiones de los órganos de administración de los referidos medios en el indicado periodo electoral son recurribles ante la Junta Electoral competente de conformidad con lo previsto en el artículo anterior y según el procedimiento que la Junta Electoral disponga.

Durante el período electoral las emisoras de titularidad privada deberán respetar los principios de pluralismo e igualdad. Asimismo, en dicho período, las televisiones privadas deberán respetar también los principios de proporcionalidad y neutralidad informativa en los debates y entrevistas electorales así como en la información relativa a la campaña electoral de acuerdo a las Instrucciones que, a tal efecto, elabore la Junta Electoral competente.

La norma como puede observarse distingue entre los medios públicos y los privados y establece más obligaciones a los primeros, pero ello no significa que los segundos no estén comprometidos con esos principios. En el derecho español, la legitimación procesal para recurrir y exigir esos principios ante las autoridades electorales competentes son: los partidos, las federaciones, coaliciones y agrupaciones que concurren a las elecciones.

El marco jurídico electoral español en la materia se ha resumido de la siguiente manera:

1) Únicamente en la prensa escrita y en las radios privadas la información debía ajustarse a los principios constitucionales que informan la libertad de expresión y el derecho a la información según el artículo 20 de la Constitución y garantizada mediante los instrumentos jurídicos ordinarios (derecho de rectificación, delitos de injurias y calumnias, etc.).

2) Por el contrario, en todas las radios y televisiones públicas y en las televisiones privadas, debía respetarse, además de las referidas normas constitucionales, el principio de pluralismo, mientras que a las televisiones privadas se les adicionaba el de igualdad y, a los 
medios públicos, el de neutralidad informativa, todos ellos garantizados por las Juntas Electorales, tanto en la información durante las elecciones como en la información de/sobre las elecciones. ${ }^{9}$

No obstante, ésta más o menos precisa regulación, los autores especializados de ese país se cuestionan la eficacia de esas prohibiciones en Internet respecto a servidores informáticos localizados fuera del territorio español.

Las prescripciones del artículo 66 de la Ley Orgánica del Régimen Electoral General han propiciado interpretaciones interesantes. Así en materia de medios públicos, los principales criterios son los siguientes:

1. Los medios públicos deben garantizar el pluralismo político y social, así como la igualdad, la proporcionalidad y la neutralidad informativa en toda su programación.

2. Los planes de cobertura informativa deben ser objeto de control previo de la Administración Electoral, incluyendo los debates, entrevistas y programas específicos de naturaleza electoral.

3. La información se sujetará a lo siguiente: a) La duración de la información dedicada a cada formación política se ajustará proporcionalmente a los resultados obtenidos en las últimas elecciones equivalentes en el ámbito de difusión del medio; y, b) Podrá proporcionarse información sobre aquellas candidaturas que no se presentaron o no obtuvieron representación en las últimas elecciones sin que en ningún caso, estas últimas puedan obtener una cobertura informativa mayor que ninguna de las formacio-

9 García Mahamut, Rosario y Rallo Lombarte, Artemi, "Neutralidad y pluralismo de los medios de comunicación en las campañas electorales: la reforma de la LOREG de 201 1", Revista Española de Derecho Constitucional, Madrid, número 98, mayo-agosto de 2013, p. 207. 
nes políticas que obtuvieron representación en las últimas elecciones.

4. Los debates electorales deben satisfacer los siguientes criterios: a) En su organización deben tomarse en cuenta los resultados obtenidos en los últimos procesos electorales; y, b) En el caso que sólo participen fuerzas mayoritarias en los debates se deberán emitir debates bilaterales o plurilaterales, o proporcionar información compensatoria suficiente sobre las demás candidaturas.

En materia de radio y televisión privada los criterios en España a seguir son:

1. Deben respetar los principios de igualdad, pluralismo, proporcionalidad y neutralidad informativa en los debates y entrevistas electorales, así como en la información relativa a la campaña electoral.

2. Los criterios que se aplican a los medios públicos, mutatis mutandis se aplican a los privados, teniendo en cuenta además para los privados la maximización de las libertades de empresa, expresión e información. ${ }^{10}$

En Francia, la comunicación institucional del gobierno emplea dos tipos de presupuestos: 1) Los gastos de base que se utilizan en internet y prensa, así como en la edición de revistas e informes; y, 2) Los gastos de comunicación en medios electrónicos, con compra o no de espacio.

El ejercicio del presupuesto en medios, se fiscaliza por el Tribunal de Cuentas, que se encarga de verificar el origen y destino

10 García Mahamul, Rosario y Rallo Lombarte, Artemi, "Neutralidad y pluralismo de los medios de comunicación en las campañas electorales: la reforma de la LOREG de 2011 ", Revista Española de Derecho Constitucional, Madrid, número 98, mayo-agosto de 2013, p. 219. 
de los recursos y la manera en la que se asignan los contratos a las empresas privadas de comunicación.

La comunicación gubernamental en Francia, tiene las siguientes características: 1) Las campañas de información deben garantizar el interés general; 2) Es obligatorio transparentar la asignación de recursos a medios privados para comunicación social; 3) Limitación de acciones de comunicación en tiempo preelectoral y electoral -se impone el principio como en España de neutralidad de los medios-; y, 4) La creación de un servicio de información del gobierno existente desde 1976 que centraliza las políticas en la materia de información gubernamental. Además, existe el Consejo Superior del Audiovisual que autoriza los contenidos audiovisuales de los medios.

En Italia la información gubernamental tiene los siguientes fines -Ley 150/2000-: 1) Divulgar en la sociedad el contenido de las leyes; 2) Difundir las competencias y funciones de las autoridades; 3) Informar a la sociedad sobre los servicios públicos; 4) Difundir asuntos de interés público y social; 5) Explicar a la sociedad los procedimientos administrativos; y 6) Promover la imagen de las instituciones y del Estado Italiano.

La publicidad gubernamental en Italia en tiempos electorales se prohíbe, aún la que tiene relación con la propia actividad institucional.

Los espacios para la publicidad oficial se adquieren por el Estado a los medios privados mediante procedimientos transparentes, aunque a veces se permiten licitaciones privadas y procedimientos negociados.

En los medios públicos el tiempo asignado a los mensajes gubernamentales no debe exceder el $2 \%$ de cada hora de programación ni el 1\% del horario semanal de las estaciones y canales públicos.

En Reino Unido existen las denominadas "Guías para el Trabajo del Servicio de Información del Gobierno”. Dichas guías no son vinculantes. Las guías establecen los propósitos de la publicidad gubernamental: 1) Adecuarse a las competencias y responsabili- 
dades gubernamentales; 2) la información debe ser objetiva y no tendenciosa; 3) La información gubernamental no debe tener fines partidistas o políticos; y, 4) El gasto en publicidad gubernamental debe ser mesurado.

Existen en Reino Unido principios para los funcionarios públicos involucrados en la publicidad gubernamental, que son: imparcialidad, neutralidad y no discriminación a los medios privados en la asignación de contratos.

En Reino Unido la publicidad oficial no puede emplearse para influir en las elecciones, consultas, ni para influir en el proceso legislativo ni para proponer la modificación de una ley, ni para incidir en la autonomía de los gobiernos locales, ni para promover los intereses de ningún partido.

iv. La publicidad gubernamental en México antes de la LEY VIGENTE

En México, la expresión neutralidad aplicable a los medios de comunicación electrónica es casi desconocida. Las normas son más bien exiguas. El artículo 134 se ocupa del ejercicio imparcial de los recursos por parte de los servidores públicos y de los principios que deben regir la publicidad gubernamental, pero carecemos de un desarrollo sobre la neutralidad como en Europa.

La reforma electoral de 2007, en esto no modificada sustancialmente por la de 2014, determinó en materia de medios de comunicación electrónica lo siguiente:

1. Los partidos pueden acceder a la radio y televisión a través de los tiempos oficiales.

2. El INE es la única autoridad facultada para administrar estos tiempos. 
3. Los partidos y candidatos no pueden adquirir y/o comprar tiempos en radio y televisión. Bajo determinados supuestos, ello puede ser causa de nulidad electoral.

4. El criterio para distribuir el tiempo oficial durante las campañas entre los partidos es el del financiamiento público $-70 \%, 30 \%-$.

5. Las personas no pueden adquirir o comprar tiempos en radio y televisión a favor o en contra de un partido o candidato.

6. No se pueden contratar mensajes políticos en el extranjero para ser transmitidos en México.

7. No se podrán realizar expresiones que calumnien a las personas.

8. La publicidad gubernamental está prohibida durante las campañas.

9. La propaganda pública está restringida, tendrá carácter institucional y no puede ser personalizada, no debe contener la voz e imagen de los funcionarios públicos.

10. Se reguló con muchas críticas el derecho de réplica.

De los asuntos nacionales, entre otros: caso Moreira Valdés (SUPJRG-215/2005), caso Pérez Magaña (SUP-RAP-7/2011 y acumulado SUP-RAP-22/2011), caso Núñez Flores (SUP-RAP-81/2010, SUP-RAP-83/2010，SUP-RAP-84/2010，SUP-RAP-85/2010 y SUP-RAP-86/2010), caso Sodi (SUP-RAP-234/2009 y acumulados), y, caso Guevara Espinoza (SUP-RAP-280/2009), no se advierte un compromiso de los tribunales electorales nacionales con el pluralismo y la neutralidad de los medios. ${ }^{11}$

Una autora dice en contra de la neutralidad de los medios y a favor de la pluralidad de los mismos, lo siguiente: "El proble-

11 Pérez de la Fuente, Óscar, Libertad de expresión y discurso político, México, Tirant Lo Blanch, 2015, p. 175. 
ma principal de la legislación mexicana es la falta de coherencia y adopción, al menos en el discurso, de una acepción irreal de la equidad. Los políticos a veces parecen buscar la igualdad absoluta, como en las alegaciones del PRD sobre la campaña electoral de 2012, cuando admitió que la cobertura de los medios fue justa en cantidad de tiempo otorgado a las fuerzas políticas, pero no en el contenido: "TV mexiquense transmitió once horas con solo menciones positivas a Enrique Peña Nieto, cinco horas de menciones negativas de Josefina Vázquez Mota, y casi cuatro horas de menciones positivas, neutras y negativas de Andrés Manuel López Obrador" (Notimex 2012). Otros líderes de izquierda han hablado en términos similares, lo que demuestra que utilizan un concepto erróneo e irreal de equidad. Esas voces, aparte de la obsesión por la equidad (en cantidad y contenido) de los asuntos electorales demuestra el miedo de la crítica y un gran desprecio por la opinión pública, o "el pueblo", que es incapaz de pensar y tomar decisiones, sino que depende de "la voz de los medios, a los que acusa de parcialidad y complot, (que) tienen la capacidad de lobotomizar a las masas a placer, como si los ciudadanos fueran incapaces de tomar decisiones libremente por el hecho de encender la televisión... Todos postulan que los medios sean neutrales, como si fuera algo posible o, incluso, deseable. Sin embargo, el problema real del mercado mediático en México no es la objetividad, sino la pluralidad...". ${ }^{12}$

Sostener puntos de vista cómo lo hace la autora precedente es no considerar el papel inmenso que desempeñan los poderes fácticos mediáticos en el país, y pensar que la libertad de expresión y el derecho a la información son mercancías y no bienes públicos. Los medios de comunicación electrónicos no son simples empresas privadas, son algo más que eso, sus negocios los realizan empleando un bien de la nación, el espectro radioeléctrico, que tiene una di-

12 Gilas, Karolina M., Libertad de expresión en el ámbito electoral en México (a la luz de los estándares internacionales), México, Tirant Lo Blanch, 2016, pp. $118-121$. 
mensión pública y social, por lo que la orientación que desempeñan no es privada, es social, y sus fines deben guiarse por la garantía de los derechos humanos y los principios democráticos. ${ }^{13}$

Los factores reales de poder, tanto nacionales como internacionales, suelen colonizar y determinar el funcionamiento de las instituciones. Es bien sabido que en los Estados de Derecho contemporáneos importa sobre todo saber o conocer el poder que se encuentra detrás de las estructuras formales del Estado, pues esos poderes son los que definen el alcance de los poderes formales. De nada sirve, por ejemplo, estudiar el Derecho Constitucional de un país, si ese estudio no viene acompañado por el de los factores reales de poder que determinan los significados de la Constitución.

No ganamos mucho analizando el orden jurídico formal mexicano si no lo vemos desde el papel que sobre él desempeñan los partidos, los sindicatos, las organizaciones empresariales, los medios de comunicación electrónicos, las trasnacionales, el gobierno de los Estados Unidos y, las organizaciones financieras internacionales. Esos son los auténticos poderes que en buena medida - tal vez, no de manera mecánica, pero si determinante- condicionan el actuar de los poderes y del orden jurídico formal. Bien podría decirse que los poderes formales y el orden jurídico son el reflejo de los intereses, pactos, acuerdos y decisiones de los factores reales de poder. Casi siempre las normas sobre ellos son escasas, ambiguas e insuficientes.

Sobre los medios de comunicación electrónica hay como se sabe una insuficiencia mayúscula, la nueva Ley de Telecomunicaciones de 2014 no responde a las exigencias de una democracia pluralista y de un Estado de Derecho auténtico, porque se ha mercantilizado un bien del dominio público y se concentran groseramente las concesiones de los medios electrónicos en unas cuantas empresas. Los organismos financieros internacionales durante décadas han influido

13 Villamil, Jenaro, "Derecho a la información, la otra gran desigualdad en México", en Florescano, Enrique y Cossío, Ramón D. (coordinadores), Hacia una nación de ciudadanos, México, Fondo de Cultura Económica, 2014, p. 292. 
en nuestra economía y esa influencia no se encuentra normada en modo alguno, no existen además los controles institucionales para supervisarla y fiscalizarla.

Las soluciones a las amenazas que representan los poderes fácticos pasan por, entre otras, las siguientes medidas: 1) preservar al Estado y fortalecerlo mediante la integración de la democracia ciudadana, ello implica democratizar y transparentar sus instituciones e incorporar medios de democracia participativa y deliberativa; 2) aprobar una estricta legislación antimonopolios; 3) determinar que los poderes fácticos son sujetos obligados de las normas de transparencia y acceso a la información; 4) obligar a que los poderes fácticos tengan una vida interna democrática (partidos, sindicatos, organizaciones empresariales, medios de comunicación electrónicos, iglesias, etcétera); 5) impedir cualquier privilegio fiscal injustificado o de otro tipo que favorezca a los poderes fácticos; 6) reformar las instituciones internacionales, a fin de abrirlas y democratizarlas; 7) reestructurar el sistema financiero internacional para transparentarlo y hacerlo más justo; 8) extraer del ámbito del comercio y la mercantilización recursos como la salud, la educación, la cultura, etcétera; 9) mundializar el constitucionalismo y las estructuras constitucionales de control del poder a fin de que las relaciones económicas y otras, producto de la globalización, no queden al margen del Derecho y del control ciudadano; y, 10) promover un contrato global para la satisfacción de las necesidades básicas, dirigido a suprimir las ilegítimas desigualdades socioeconómicas entre clases, géneros, etnias, regiones y naciones, etcétera.

La ONU y la OEA se han preocupado por la concentración mediática en México. Frank La Rue, relator especial de la ONU en materia de libertad de expresión, indicó en 2011 en relación con la libertad, pluralismo y diversidad en el debate democrático, que: “...sigue existiendo en México una alta concentración en la propiedad y el control de los medios de comunicación a los que se les ha asignado frecuencias radioeléctricas. El Relator Especial insta al 
Congreso de la Unión y al Ejecutivo Federal a adoptar una legislación conforme con los organismos internacionales para desconcentrar dicho sector, y que contribuya a generar un espacio mediático plural y accesible a todos los sectores de la población" (Informe del relator especial sobre la promoción y protección del derecho a la libertad de opinión y de expresión, Asamblea General de Naciones Unidas, 19 de mayo de 2011 (A/HRC/17/27/ Add.3).

En la parte conducente del informe de Frank La Rue se recomienda al Estado mexicano lo siguiente: "a) Adoptar un marco normativo que brinde certeza jurídica; promueva la desconcentración de la radio y la televisión y contribuya a generar un espacio mediático plural y accesible a todos los sectores de la población; b) Asegurar la existencia de medios públicos verdaderamente independientes del Gobierno, con el objetivo de fomentar la diversidad y garantizar a la sociedad, entre otros, ciertos servicios educativos y culturales; c) Crear un marco legal claro, preestablecido, preciso y razonable que reconozca las características especiales de la radio comunicación comunitaria y que contenga procedimientos sencillos y accesibles para la obtención de las frecuencias; d) Grear un órgano independiente del gobierno que regule la radio y la televisión; e) Establecer criterios objetivos, claros, transparentes y no discriminatorios en la asignación de publicidad oficial para todos los niveles y órdenes de gobierno".

Por su parte, la Dra. Catalina Botero, Relatora Especial para la libertad de expresión de la OEA, en su informe final hecho público el día 7 de marzo de 2011 señala: "La Relatoría observa que en México sigue existiendo una alta concentración en la propiedad y el control de los medios de comunicación a los que se ha asignado frecuencias radioeléctricas. La información entregada a la Relatoría por el Presidente de la Comisión de Radio, Televisión y Cinematografía del Senado de la República indica que más del 90\% de las frecuencias de televisión se encuentran en manos de sólo dos empresas. La información proporcionada por organizaciones de la 
sociedad civil coincide en señalar este alto grado de concentración. El Presidente de la Comisión de Radio y Televisión y Cinematografía del Senado también informó a la Relatoría que con relación a la radio comercial, el 76\% del sector se encuentra en manos de 14 familias, y que $47.8 \%$ de las emisoras pertenecen a cuatro grandes cadenas" (Informe de la relatoría especial para la libertad de expresión, Comisión Interamericana de derechos Humanos, OEA, 7 de marzo de 2011).

Las preocupaciones de los dos relatores especiales de la ONU y la OEA son más que fundadas y las recomendaciones de sendos informes debieron ser adoptados por el Estado mexicano desde hace mucho tiempo. Sin embargo, a pesar de las últimas reformas constitucionales y legales de 2013 y 2014, los medios de comunicación siguen estando por encima de las autoridades constituidas, por las siguientes razones: 1) El Congreso de la Unión no ha aprobado una la ley secundaria democrática en materia de publicidad gubernamental -la Ley General de Comunicación Social de 11 mayo de 2018 es un ordenamiento predemocrático; 2) El Congreso de la Unión no ha aprobado reformas a la ley de telecomunicaciones y radiodifusión de 2014 que estén en consonancia con una futura democracia pluralista que aún no se materializa; 3) No existe en México una autoridad independiente y realmente autónoma que regule a los medios de comunicación electrónica de carácter privado y público; 4) Hay un duopolio televisivo en donde dos empresas Televisa y Televisión Azteca concentraban antes de la reforma en materia de telecomunicaciones de 11 de junio de 2013 más del 90\% del espectro radioeléctrico; 5) En la radio, unas cuentas empresas concentran casi el 50\% del espacio radioeléctrico; 6) Los 48 minutos diarios de que disponen los partidos en las campañas para transmitir propaganda electoral, no impiden que los grandes medios de comunicación electrónica en México, vía entrevistas, programas especiales, infomerciales o noticieros, otorguen tiempo extra a sus candidatos favoritos en detrimento de la equidad en la contienda 
con lo que la reforma electoral ya citada queda burlada; 7) Las autoridades electorales - INE y Tribunal Electoral del Poder Judicial de la Federación- se han visto tibias y tímidas a la hora de imponer sanciones a los medios de comunicación electrónica, de esta suerte y hasta el momento, ningún medio de comunicación ha perdido la concesión o se le ha suspendido su programación por violaciones a la legislación electoral; 8) Las multas que han fijado las autoridades electorales federales a los medios privados en un gran porcentaje no se han podido cobrar porque éstas no tienen competencias directas y suficientes para cobrarlas; 9) Los medios de comunicación electrónica han intentado impedir la mínima regulación administrativa de las autoridades electorales; y, 10) Las voces críticas y alternativas al gobierno no tienen presencia equitativa en los medios de comunicación electrónica.

\section{v. Descripción de la Ley General de Comunicación SOCIAL.}

La ley fue publicada el 11 de mayo de 2018 en el Diario Oficial de la Federación. Se trata de una ley general que obliga a los poderes y autoridades de los tres niveles de gobierno, respecto a la propaganda gubernamental bajo cualquier modalidad de comunicación social. Es reglamentaria del párrafo octavo del artículo 134 de la Constitución.

Las normas que dan origen a esta ley son, entre otras, el párrafo octavo del artículo 134 de la Constitución que fue introducido por la reforma constitucional electoral de 2007, los artículos 6 y 7 de la Ley Fundamental, así como el artículo 13 de la Convención Americana sobre Derechos Humanos, el artículo 19 del Pacto In- 
ternacional de Derechos Civiles y Políticos, y el artículo 19 de la Declaración Universal de Derechos Humanos. ${ }^{14}$

Esos fundamentos constitucionales y convencionales nos indican que la información emitida por el Estado debe cumplir con objetivos claros, precisos y legítimos. La publicidad oficial debe tener un propósito de utilidad pública y no puede ser arbitraria para evitar la censura indirecta. La publicidad oficial no puede ser una forma de presión que actúe como premio o castigo que tenga por objeto condicionar la línea editorial de un medio según la voluntad de quien ejerce la presión. ${ }^{15}$

El artículo 13 de la Convención Americana sobre Derechos Humanos introdujo la prohibición de medios indirectos para restringir la libertad de expresión, tales como el abuso de controles oficiales o particulares de papel para periódicos, de frecuencias radioeléctricas, o de enseres y aparatos usados en la difusión de información o por cualesquiera otros medios encaminados a impedir la comunicación y la circulación de ideas.

México en materia de publicidad oficial ya había sido, antes de la aprobación de la Ley, objeto de observación internacional. La visita conjunta de los Relatores Especiales sobre la Libertad de Expresión de la Comisión Interamericana de Derechos Humanos y la Organización de Naciones Unidas en el año de 2017 mostró preocupación por las leyes que se podían aprobar, en particular insistieron para que esas leyes no establecieran restricciones arbitrarias o desproporcionadas. ${ }^{16}$

14 Villanueva, Ernesto, Régimen constitucional de las libertades de expresión e información en los países del mundo, México, editorial Fragua, 1997.

15 Comisión Interamericana de Derechos Humanos, Relatoría Especial para la Libertad de Expresión, "Principios sobre regulación de la publicidad oficial y libertad de expresión en el Sistema Interamericano de Protección de Derechos Humanos", 7 de marzo de 2011, párrafo 10.

16 Observaciones preliminares del Relator Especial de la ONU sobre la libertad de expresión y el Relator Especial sobre la libertad de expresión de la CIDH 
Desgraciadamente la Ley aprobada, como lo probaremos en el recuento que a continuación haremos, no cumplió con los preceptos constitucionales y convencionales arriba señalados ni con los estándares internacionales, por eso ha sido impugnada en su totalidad ante la Suprema Corte de Justicia de la Nación. La Ley General de Comunicación es integralmente inconstitucional. Sus preceptos más neutrales deben ser también expulsados del sistema normativo nacional porque son parte de una estructura normativa que tiene por propósito vulnerar el orden constitucional y convencional.

$\mathrm{Su}$ artículo 2 indica que la propaganda gubernamental debe cumplir con los principios de eficiencia, eficacia, economía, transparencia y honradez. Los topes del gasto en propaganda gubernamental serán definidos en los presupuestos. La Ley no prevé topes máximos ni desarrolla adecuadamente cada uno de los principios, ${ }^{17}$ en contra de lo dispuesto por la reforma constitucional electoral de 2014 que estableció en su artículo tercero transitorio lo siguiente:

El Congreso de la Unión deberá expedir, durante el segundo periodo de sesiones ordinarias del segundo año de ejercicio de la LXII Legislatura, la ley que reglamente el párrafo octavo del artículo 134 de esta Constitución, la que establecerá las normas a que deberán sujetarse los poderes públicos, los órganos autónomos, las dependencias y entidades de la administración pública y de cualquier otro ente de los tres órdenes de gobierno, y que garantizará que el gasto en comunicación social cumpla con los criterios de eficiencia, eficacia, economía, transparencia y honradez, así como que respete los topes presupuestales, límites y condiciones de ejercicio que establezcan los presupuestos de egresos respectivos.

después de su visita conjunta de 27 de noviembre de 2017 -4 de diciembre de 2017-, punto 49.

17 Resolución del amparo en revisión 1359/ 2015 de 15 de noviembre de 2017, Primera Sala. Suprema Corte de Justicia de la Nación. Ministro ponente: Arturo Zaldívar Lelo de la Larrea. 
Llama la atención que no exista como principio el de neutralidad, mismo que es recogido en el derecho comparado.

En el artículo 3 se establece que son sujetos obligados todas las autoridades de la República.

El artículo 4 precisa el significado de los conceptos básicos de la ley: a) campañas de comunicación social que son las que difunden las acciones o logros de Gobierno o estimulan acciones de la ciudadanía para acceder a algún beneficio público; b) coemisión de campaña, que es la difusión en la que participan de manera coordinada dos o más entes públicos; c) entes públicos que son todas las autoridades de la República; d) estrategia anual de comunicación social es el instrumento de planeación de la difusión de la propaganda gubernamental; e) informe anual de labores o de gestión es el que prevé la legislación electoral; f) medios de comunicación son los electrónicos, impresos, complementarios, digitales y medios públicos; g) padrón es el Padrón Nacional de Medios de Comunicación; h) programa anual de comunicación social son las campañas de comunicación que derivan de la estrategia; i) recursos presupuestarios son los recursos aprobados por el poder legislativo para el fin materia de la ley; j) secretaría administradora es la secretaría de Gobernación, sus equivalentes en los estados y municipios y en el resto de los entes públicos; $\mathrm{k}$ ) sistema público es en el que se registran y se da seguimiento a las erogaciones en la materia; l) sistema de información de normatividad de comunicación es en el que se registran los programas anuales de comunicación social; m) tiempos comerciales son los adquiridos por los entes públicos; n) tiempos del Estado son los que corresponden al estado de conformidad con los artículos 251 y 252 de la Ley Federal de Telecomunicaciones y Radiodifusión; o) tiempos fiscales son el pago en especie que realizan los medios al Estado por las concesiones otorgadas; y, p) tiempos oficiales comprenden los tiempos del Estado y los fiscales.

El glosario de la Ley revisto en el artículo 4, autoriza campañas de comunicación social que van más allá de los límites que determi- 
na el artículo 134 constitucional. Tal es el caso, por ejemplo, de la comunicación social sobre logros del gobierno.

El ejercicio del gasto público en la materia debe observar -artículo 5- los siguientes principios: eficacia, eficiencia, economía y racionalidad presupuestaria, transparencia y máxima publicidad, honradez, objetividad e imparcialidad, institucionalidad, necesidad, congruencia y veracidad. Además, se debe contribuir a la igualdad de género y al respeto de la diversidad social y cultural de la Nación. Los lineamientos que emita la Secretaría de Gobernación deben cumplir con esos principios.

La última porción normativa del artículo 5 de la Ley, transgrede el principio de reserva de ley que consagra el artículo 134 de la Constitución en la materia.

En lo conducente son ordenamiento supletorio: La Ley Federal de Procedimiento Administrativo, la Ley General de Instituciones y Procedimientos Electorales, la Ley General de responsabilidades Administrativas, la Ley de Fiscalización y Rendición de Cuentas de la Federación, y la Ley General de Transparencia y Acceso a la Información Pública (artículo 6).

De manera peligrosa, el artículo 6, mezcla la libertad de expresión con la libertad de contratación de los medios de comunicación. Se trata de dos derechos fundamentales que al asimilarse hacen que se entienda que la libertad de expresión se ejerce necesariamente por medio de la contratación que realizan las empresas privadas. La libertad de expresión puede ejercerse independientemente de la contratación.

De acuerdo al artículo 7 de la Ley General de Comunicación Social, no se considera como tal, la que se difunde por mandato de la ley.

Según el artículo 8 de la Ley General de Comunicación Social, las campañas de comunicación social deberán: 1) Promover la difusión y conocimiento de los valores, principios y derechos constitucionales; 2) Promover campañas de turismo, educación, salud 
y protección civil; 3) Informar a los ciudadanos de sus derechos y obligaciones legales de aspectos relevantes del funcionamiento de los sujetos obligados, y de las condiciones de acceso y uso de los espacios y servicios públicos; 4) Cumplir con las obligaciones que en materia electoral establezca la legislación aplicable; 5) Anunciar medidas preventivas de riesgos que contribuyan a la eliminación de daños de cualquier naturaleza para la salud de las personas o el equilibrio ecológico y protección al ambiente, así como en materias de protección civil; 6) Difundir las lenguas nacionales y el patrimonio histórico de la Nación; 7) Comunicar programas y actuaciones públicas (se exceden las restricciones constitucionales del artículo 134 constitucional); y 8) Otras.

Como se puede observar el artículo 8 de la Ley va más allá de lo previsto en el artículo 134 de la Constitución. Por ejemplo, la comunicación de programas y actuaciones públicas podría implicar la promoción de logros de gobierno y personalizada de los servidores públicos. Las campañas de comunicación social deben tener exclusivamente fines institucionales y evitar cualquier elemento que en ellas favorezca a una opción ideológica, de gobierno, o que apuntale la consolidación de cualquier servidor público.

En el artículo 9 se establecen las prohibiciones. Los contenidos que no pueden difundirse: los que destaquen de manera personalizada a los servidores públicos con excepción del artículo 14 -informes anuales o de gestión-; incluyan mensajes discriminatorios, sexistas o contrarios a los valores, principios y derechos constitucionales; inciten, de forma directa o indirecta, a la violencia o a comportamientos contrarios al ordenamiento jurídico; e induzcan a la confusión con los símbolos, ideas, expresiones, diseños o imágenes empleadas por cualquier organización política y social.

Es evidente que la porción del precepto que excluye de la prohibición a los informes anuales o de gestión de los servidores públicos es abiertamente inconstitucional. Por ningún motivo los servidores públicos pueden utilizar la difusión de la comunicación social para 
realizar promoción personalizada, aunque se trate de sus informes anuales o de gestión. La excepción prevista en esta ley y en la legislación electoral es contraria desde nuestro punto de vista al artículo 134 constitucional.

El artículo 10 de la Ley incorpora otra prohibición: "Por ningún motivo el contenido de la Comunicación Social que difundan los entes públicos podrá incluir mensajes que impliquen un ataque a la moral, la vida privada o los derechos de terceros, provoque algún delito, o perturbe el orden público".

En el artículo 11 se expresa que la comunicación social que difunda programas que otorguen subsidios o beneficios directos a la población deberán incluir la siguiente leyenda: "Este programa es público ajeno a cualquier partido político. Queda prohibido el uso para fines distintos a los establecidos en el programa". El último párrafo del precepto agrega para evitar el uso clientelar y corporativo de los programas sociales que los partidos políticos no podrán emplear o referir estos programas en su propaganda de comunicación social.

El artículo 12 de la Ley dice que se procurará transmitir la comunicación social en formatos accesibles a las personas con discapacidad. Así, se deberá considerar el Lenguaje de Señas Mexicanas, y se procurará, que en las comunidades originarias la comunicación social se difunda en las lenguas respectivas. Es, como se desprende de su texto, una norma de buenos deseos. No es obligatorio que los derechos humanos de las personas con discapacidad se garanticen en la materia o que los pueblos originarios reciban la difusión de la comunicación social en sus lenguas.

La propaganda electoral, de acuerdo al artículo 13, se sujeta a lo dispuesto en las normas electorales.

De manera inconstitucional, el artículo 14 de la Ley, indica que los informes anuales de labores y de gestión no serán considerados comunicación social. Es una norma que excepciona el cumplimiento del mandato constitucional que prohíbe la promoción persona- 
lizada de los servidores públicos. Existe en la legislación electoral y en esta Ley una excepción que permite que los servidores públicos durante 7 días previos y 5 posteriores a la rendición del informe difundan logros y hagan propaganda con las actividades por ellos realizadas.

La gravedad del hecho se acentúa porque no se define la forma en la que deben contabilizarse y fiscalizarse los recursos públicos empleados para realizar esta promoción personalizada. Tampoco la norma establece límites o requisitos para esta promoción personalizada ni se precisan condiciones o prohibiciones cuando los recursos provienen de fuentes privadas. La historia política de nuestro país ilustra que la exhibición de los citados informes es un mecanismo para posicionar electoralmente a los servidores públicos. Se violenta el principio de equidad porque los servidores públicos que tienen acceso a recursos públicos para esta promoción personalizada o a recursos privados de factores reales de poder tendrán ventajas de inicio en las contiendas electorales.

Los artículos 15 a 17 de la Ley aluden a los tiempos oficiales. Los tiempos oficiales -del Estado y fiscales- serán utilizados por los entes públicos que tengan acceso a ellos para la difusión de contenidos de carácter institucional y con fines informativos, educativos, culturales y otros asuntos de interés social. Las normas establecen la distribución de los tiempos fiscales de la siguiente manera: 1) 40\% al poder ejecutivo; 2) 30\% al poder legislativo; 3) $10 \%$ al poder judicial; $y$, 4) $20 \%$ a los órganos constitucionales autónomos. La Secretaría de Gobernación, no obstante, puede reasignar estos porcentajes.

Como se puede apreciar, no se incluye en la distribución a los tiempos del Estado, los que al parecer se dejan exclusivamente para los fines electorales y seguirán regulados por la legislación electoral. También es evidente, que sobre los tiempos fiscales no existe una distribución a las entidades federativas, municipios y alcaldías. Además, el porcentaje mayor en la distribución corresponde al Poder Ejecutivo y, por si fuera poco, la Secretaría de Gobernación podrá 
reasignar los porcentajes entre los poderes y entes, lo que seguramente redundará, a pasar de la porción normativa que dice "las reasignaciones se ajustarán a la proporción prevista en este artículo", en un posicionamiento favorable del Ejecutivo en el concierto de las instituciones públicas.

El artículo 18 determina que los entes públicos federales podrán destinar recursos presupuestarios para tiempos comerciales, siempre y cuando, hayan solicitado los tiempos oficiales, y dichos tiempos no estuvieran disponibles. Los entes públicos no podrán convenir el pago de créditos fiscales, ni de cualquier otra obligación de pago a favor de la autoridad a cambio de tiempos comerciales.

Este precepto abre la puerta a la comercialización de todos los tiempos para Comunicación Social. Ante las capacidades e influencia del poder mediático en nuestro país, es muy probable que se pretexte que los tiempos fiscales y los del Estado no pueden cubrir la comunicación social de los entes públicos. Con ello, resultará que la mayor parte del tiempo en medios de radiodifusión que se destine a comunicación social serán adquiridos por las autoridades.

La ley no establece tope de gasto para comunicación social a ser fijado en los presupuestos, tampoco precisa el porcentaje máximo de gasto por cada medio de comunicación privada. Lo que implica que podría seguir existiendo un gasto excesivo para la comunicación social, tanto la prevista en los presupuestos como en las decisiones gubernamentales los sobre ejercicios en esos rubros, y que ciertos medios resultarán más favorecidos que otros por esas decisiones de gasto.

La ausencia de regulación en materia de topes de gasto en materia de comunicación social, así como de límites en la adquisición a favor de determinados medios es campo propicio no sólo para la discrecionalidad sino para la arbitrariedad en las contrataciones. Desde el punto de vista gubernamental este elemento normativo constituye un poderoso instrumento de censura contrario al artículo 
6 constitucional. Los gobiernos decidirán a quién contratar y con cuánto, y a quién no.

El artículo 19 de la Ley para mostrar respeto a la Constitución, al artículo 134, señala que las contrataciones deberán apegarse a la legislación y normatividad en materia de adquisiciones, arrendamientos y servicios.

Respecto a las campañas de carácter industrial, mercantil y las de promoción y publicidad que generen algún ingreso para el Estado, éstas no podrán difundirse en los tiempos oficiales. Tal regulación se realizará a través de Lineamientos que emitan las Secretarías Administradoras -artículo 20-.

El artículo 21 señala que durante las campañas se debe suspender la difusión de comunicación social. Se exceptúan de lo anterior: las campañas de información de las autoridades electorales; las relativas a los servicios educativos y de salud; las de protección civil en casos de emergencia; y las que autorice el Consejo General del INE.

La norma citada no garantiza la equidad en materia electoral. El plazo de las campañas es muy breve. La norma debió prohibir la difusión de comunicación social gubernamental durante el lapso de todo el proceso electoral. Por otra parte, se faculta al Consejo General del INE a difundir comunicación social gubernamental más allá de las hipótesis establecidas en el artículo 134 constitucional. Esa porción normativa resulta inconstitucional a todas luces.

El artículo 22 de la Ley indica que la Secretaría Administradora planea y evalúa la comunicación social de los gobiernos. Es obvio que no existe una autoridad externa e independiente que evalúe los programas e implementación de la comunicación social gubernamental, lo que confiere un gran poder a la autoridad administradora, pues ella planea, ejerce los recursos públicos en la materia, y posteriormente evalúa las políticas de comunicación social de los gobiernos. Desde nuestra lectura, debió haberse previsto una autoridad independiente del poder ejecutivo que se encargara de la tarea de la evaluación. La norma en los términos aprobados no 
brinda confianza ni certeza sobre las políticas de comunicación social gubernamentales. La autoridad administradora es juez y parte en el proceso completo.

En el artículo 23 se señalan los elementos que deben observar los entes públicos en la elaboración de su estrategia anual de comunicación social. Deben satisfacerse las siguientes variables: Misión y visión del ente público; objetivo u objetivos institucionales y objetivo de la estrategia anual de comunicación social; metas nacionales y/o estrategias transversales relacionadas con los objetivos del Plan Nacional de Desarrollo; los programas sectoriales o especiales al ente público; y, temas específicos vinculados con la comunicación social.

Los entes públicos que cuenten con recursos presupuestales deben elaborar además de la estrategia -artículo 24 de la Ley- un programa anual de comunicación social, el que podrá incluir: mensajes sobre programas y actividades gubernamentales; acciones o logros del gobierno; y mensajes tendientes a estimular acciones de la ciudadanía para acceder a algún servicio o beneficio público.

Por medio del programa anual de comunicación social, dada la ambigüedad de sus contenidos, puede comprender actividades gubernamentales incompatibles con las prohibiciones del artículo 134 de la Constitución. La Ley no excluye la comunicación social que entraña logros gubernamentales. Ésta es una forma abierta de propaganda para posicionar al gobierno en turno y a sus servidores públicos de cara al electorado. A la ley le falta contundencia para que la comunicación social gubernamental sólo tenga fines institucionales y no de promoción personalizada, directa o indirecta, de los servidores públicos en funciones.

Dice el artículo 25 que las dependencias y entidades de las administraciones públicas deberán presentar su estrategia y programa anual correspondiente y enviarlo a la Secretaria Administradora, previo registro en el Sistema de Información de Normatividad de Comunicación u homólogo, en la primera quincena de enero de 
cada año. La Secretaría Administradora emitirá las observaciones y en su caso autorizará la estrategia y los programas anuales.

El artículo 26 de la Ley señala que en la ejecución de sus programas anuales de comunicación social, los entes públicos deberán atender a los siguientes criterios: 1) Que las campañas de comunicación social tengan relación directa con las atribuciones y facultades de los sujetos obligados; 2) Que los recursos a utilizar sean proporcionales a los objetivos de la campaña; 3) Que las herramientas y medios utilizados para la difusión de la campaña sean seleccionados de manera efectiva a fin de que la hagan llegar al público al que vaya dirigida; 4) Que haya objetivos claros y precisos para comunicar; 5) Que se establezcan metas de resultados y procedimientos de evaluación de las campañas; 6) Utilizar los tiempos oficiales conforme a las disposiciones legales; y, 7) Que tengan carácter institucional y fines informativos, educativos o de orientación social.

De la redacción del precepto no se aprecia que se fije tope alguno de gasto general. Tampoco se considera como obligación un monto máximo a destinar a cada medio de comunicación. En cuanto a la evaluación de la propaganda, ésta no es externa ni ciudadana.

En el artículo 27 de la Ley se remite a los Lineamientos de la Secretaría Administradora para que ésta determine cómo finalmente deben regularse las estrategias, programas y campañas de comunicación social. Existe una clara violación al principio de reserva de ley en esta materia, la que está prevista en el artículo 134 de Constitución, lo que hace más poderosa a la Secretaría Administradora, la que en última instancia fijará las condiciones de la comunicación social de los entes.

El artículo 28 estatuye la función de registro y vigilancia de la Secretaría Administradora sobre las condiciones que la propia Secretaría haya definido en los Lineamientos.

Después que se autoriza la estrategia y el programa anual de campañas de cada ente público, la Secretaría autoriza caso por caso 
las campañas de comunicación social respectivas -artículo 29 de la Ley-.

En el caso de los poderes legislativo, ejecutivo, y órganos autónomos se señala -artículo 30- que éstos deberán regular en sus disposiciones internas procedimientos análogos a los del ejecutivo para la aprobación de la estrategia, programa y autorización de campañas particulares, al igual que la ejecución y evaluación de las mismas.

Los artículos 31 y 32 norman los mensajes extraordinarios. Se establece que éstos pueden autorizarse más allá del programa anual de comunicación social, y derivan en su necesidad del carácter emergente, coyuntural de una situación que no haya sido prevista pero que esté debidamente justificada. En el ejecutivo, los mensajes extraordinarios los aprueban la Secretaría Administradora, en los demás poderes y órganos autónomos los mensajes extraordinarios serán autorizados según lo prevean sus disposiciones internas.

Para la vigilancia y control de la contratación de la comunicación social se determinan las autoridades competentes para el efecto. En el ejecutivo ello será realizado por la Secretaría de la Función Pública, en los Estados la competencia recae en la Secretaría que tenga atribuciones similares, y en los demás poderes y órganos autónomos en la Auditoría Superior de la Federación o a las auditorías estatales, según sus respectivas competencias -artículos 33 y 34 de la Ley-.

Los artículos 35 a 37 de la Ley, le confieren un gran poder a la Secretaría de Gobernación. Habrá un padrón nacional de medios de comunicación a cargo de esta Secretaría. Los medios que pretendan acceder a la contratación deben estar inscritos en ese padrón. La Secretaría de Gobernación mediante Lineamientos organizará al padrón, lo que nuevamente implica una violación al principio de reserva de ley.

En los artículos 38 y 39 de la Ley, se dota a la Auditoría Superior de la Federación y a sus homólogas en los Estados, la revisión y fiscalización final del gasto en materia de comunicación social. Cuando existan conflictos de competencias entre las auditorías es- 
tatales y la federal, la competencia se surtirá a favor de la Auditoría Superior de la Federación.

Es obligación de los entes públicos informar sobre los montos destinados a gastos relativos a campañas de comunicación social. La información debe estar desglosada por tipo de medio, proveedores, número de contrato y concepto o campaña -artículo 40-.

El artículo 41 de la Ley dice que cada uno de los entes públicos incorporará un informe semestral sobre el gasto en publicidad oficial en su portal de transparencia. Igualmente, en el artículo 42 se expresa que la Secretaría Administradora informará bimestralmente a la Cámara de Diputados o los Congresos locales, respectivamente, a través de la Comisión competente, sobre la ejecución de los programas y actividades gubernamentales. De la misma cada año se debe informar a la Cámara de Diputados y a los Congresos locales -artículo 43-.

De manera vaga, el artículo 44 establece las infracciones, sin añadir las sanciones. Son infracciones: 1) Difundir campañas de comunicación social violatorias de los principios establecidos en el artículo 5 de la ley; 2) Exceder límites y condiciones en los informes de labores de los servidores públicos; y 3) Incumplir con las obligaciones que determina la ley.

En el artículo 45 se señala que de las infracciones se debe dar vista al superior jerárquico, o en su caso presentar quejas administrativas o denuncias penales ante las autoridades competentes. No hay sanciones para los titulares o administradores de los medios de comunicación privados que participen en los hechos.

La Ley entra en vigor el 1 de enero de 2019. En un plazo de 120 días a partir de la publicación de la Ley se debieron realizar las adecuaciones reglamentarias. El Padrón Nacional de Medios de Comunicación deberá crearse una vez aprobado el Presupuesto de Egresos de 2019. El resto de la legislación debe ser armonizada respecto al Decreto que aprueba la Ley General de Comunicación Social. 
VI. LA ACCIÓN DE INCONSTITUCIONALIDAD DE LA MiNORÍA SENATORIAL PRESENTAda EN CONTRA DE LA Ley General de Comunicación SOCIAL.

Un grupo de senadores que reunió el 33\% de legisladores requerido para ese efecto, promovió el 11 de junio de 2018 ante la Suprema Corte de Justicia de la Nación, acción de inconstitucionalidad en contra de la Ley General de Comunicación Social publicada el 11 de mayo de 2018 en el Diario Oficial de la Federación. Los senadores consideraron que la Ley violentaba los artículos 1, 2, 3, 6 aparatado B, 7, 28 y 134 de la Constitución, así como los artículos 13.2 y 13.3 de la Convención Americana sobre Derechos Humanos, al igual que el artículo 19 de la Declaración Universal de Derechos Humanos.

Los impugnantes estimaron que la Ley General de Comunicación Social no cumple con los objetivos que propone su propio decreto aprobatorio en su exposición de motivos. Desde su punto de vista la ley no se cumple con tres propósitos torales: 1) Reducir el uso excesivo de recursos para la contratación de publicidad oficial; 2) Terminar la parcialidad en la aplicación de recursos públicos para gastos de comunicación social oficial; y, 3) Poner fin a la contratación de espacios de publicidad oficial para promociones personales de servidores públicos.

Entre los argumentos generales para expresarse en contra de la ley manifestaron que:

1. La Ley General de Comunicación Social no establece criterios claros y objetivos para la asignación de publicidad oficial. Se sostiene que se debieron determinar criterios de asignación precisos. Los artículos 15, 16 y 17 de la Ley fijaron "criterios" de manera ambigua respecto a su designación y contenido. El artículo 18 permite a los entes públicos destinar recursos a tiempos comerciales, cuando 
no estuvieran disponibles los tiempos solicitados, sin embargo, no se determinaron criterios para que dichos supuestos procedan, ni si esos gastos son parte del ejercicio ordinario o extraordinario.

2. La Ley General de Comunicación Social no cumplió con la obligación constitucional para establecer topes de gasto presupuestal. No se satisface por tanto el mandato del constituyente permanente.

3. La ley debió prohibir tajantemente la promoción personalizada en el marco de los informes anuales. No obstante, el artículo 4, fracción $\mathrm{V}$ y el artículo 14 permiten la difusión personalizada de servidores públicos y el uso de gasto público para la difusión de los mismos contrario a lo establecido en el texto constitucional.

4. La ley general de comunicación social favorece la discrecionalidad en el manejo de la publicidad oficial. La existencia de tiempos del Estado, fiscales, oficiales, informes de labores, así como tiempos comerciales, y los criterios definidos en el artículo 8 de la Ley General de Comunicación Social, abonan a la discrecionalidad en el manejo de la publicidad oficial.

5. La Ley General de Comunicación Social mantiene la censura indirecta al no haberse establecido de manera clara y precisa los criterios de asignación. Los medios para recibir publicidad oficial silenciaran su crítica al gobierno en turno. Es inconstitucional que se permita contratar tiempos comerciales.

6. La Secretaría de Gobernación y las Secretarias de Gobierno en los Estados son tanto autoridades administradoras y evaluadoras. Se concentra en una sola autoridad atribuciones que deben corresponder a autoridades diferenciadas. 
7. No existe una fiscalización externa al ejecutivo que evalúe y fiscalice la asignación de la publicidad oficial.

8. No existen tipos ni sanciones precisas a los funcionarios y personas que apliquen indebidamente la ley.

En el primer concepto de invalidez los senadores consideraron que la Ley General de Comunicación Social vulnera el derecho a la libertad de expresión. Se esgrime que la Ley genera espacios de discrecionalidad a las autoridades para contratar publicidad oficial a los medios cercanos al gobierno. El ejercicio arbitrario del presupuesto en materia de comunicación social constituye un mecanismo de restricción o limitación indirecta de la libertad de expresión, el que se encuentra proscrito por la Constitución.

Se argumenta que la supresión de los ingresos a los medios de comunicación que reciben publicidad oficial puede implicar que ya no tengan recursos para poder seguir funcionando. La dependencia de los medios de comunicación al gasto en comunicación social del gobierno es una situación que sin lugar a dudas supone una amenaza a la libertad de expresión. En el caso mexicano, la mayoría de los medios ha dependido de la publicidad oficial durante mucho tiempo, lo que otorga a los funcionarios una gran influencia para presionar sobre la cobertura de ciertas noticias. Por eso, el temor a perder la asignación provoca silencio sobre cuestiones de interés público. El esquema previsto en la ley induce a apoyar las opiniones del gobierno. Su existencia permite determinados discursos que constituyen un efecto amedrentador en los periodistas, pues se disuade la crítica al gobierno en turno.

Los senadores dicen que estamos en presencia del "chilling effect" estudiado por la Corte Suprema de los Estados Unidos. Ese efecto intimidatorio es una forma de autocensura para no expresar discursos que pueden acarrearle consecuencias negativas al periodista 
o al medio. ${ }^{18}$ La Ley General de Comunicación Social no permite cambiar el sistema de contratación de los gobiernos mexicanos. En México se seguirá privilegiando vía la contratación a ciertos medios de comunicación y excluyendo a otros, sin criterios precisos.

En el segundo concepto de invalidez se esgrime que la Ley General de Comunicación Social incumple el mandato establecido por el órgano constituyente y por la Suprema Corte de Justicia de la Nación. Lo anterior se señala porque a juicio de los impugnantes no se cumple con la sentencia recaída en el amparo en revisión 1359/2015. En esa resolución la Corte ordenó al Congreso a cumplir con el artículo tercero transitorio del decreto de la reforma constitucional de 10 de febrero de 2014 y, en consecuencia, a emitir una ley que regule el párrafo octavo del artículo 134 constitucional.

A pesar del mandato constitucional, la ley no definió cómo se cumplirá con los principios de eficacia, eficiencia, transparencia, economía y racionalidad presupuestaria, honradez, objetividad e imparcialidad. La ley tampoco estableció con prolijidad las sanciones y los procedimientos para los casos en que se viole el párrafo octavo del artículo 134 constitucional. La ley igualmente no contempla criterios precisos para la asignación de recursos públicos entre los medios con lo que se mantiene la discrecionalidad y arbitrariedad en la asignación. La ley no estableció topes generales en publicidad oficial ni los topes para el gasto máximo en cada medio.

En el tercer concepto de invalidez se considera infringida la libertad de imprenta. Ello se esgrime porque la Ley contempla la creación de un Padrón Nacional de Medios de Comunicación que estará bajo la coordinación de la Secretaría de Gobernación, que a su vez emitirá los lineamientos y reglas con las que dicho Padrón operará. Esto supone una especie de club en que aquellos medios de comunicación que aspiren a obtener contratos de publicidad oficial

18 Virginia v. Black, 538 US 343, 367 (2003); New York v. Ferber, 458 US 747, 769, n. 24 (1982). 
deberán cubrir los requisitos para entrar a dicho club. Los medios que se adapten a lo que el Estado disponga se verán beneficiados con fuertes sumas, lo que pone en riesgo el derecho colectivo a la libertad de expresión.

Los Senadores estiman en este tercer concepto de invalidez que el Estado, tiene a través de la Ley General de Comunicación Social y el Padrón Nacional de Medios de Comunicación que ésta prevé, un instrumento para controlar a la prensa. Se trata de una forma de censura indirecta ejercida por el peso del dinero que los poderes públicos gastan en publicidad gubernamental, mismos que distribuyen con amplia discrecionalidad.

En el cuarto concepto de invalidez se aprecia violado el derecho de las audiencias. Se expone que el derecho de las audiencias implica recibir contenidos que reflejen el pluralismo ideológico, político, social, cultural y lingüístico de la nación. La Ley General de Comunicación Social no señala un mecanismo específico para que los ciudadanos puedan distinguir los mensajes producto de la publicidad oficial, sobre todo cuando se trata de tiempos comerciales, tampoco se establecen regalas para que los usuarios de las audiencias constaten la veracidad de los mensajes que difunde el gobierno, y no se reglamentan los criterios que deben observarse para elegir a los medios de comunicación que transmiten los mensajes oficiales.

Los derechos de las audiencias implican: Una amplia gama de canales comunicativos que tiendan a expresar la diversidad social, política y cultural nacional y de otros países; la posibilidad de participar en los procesos de producción de información de interés público; que los usuarios sean representados dignamente en formatos mediáticos factuales y ficcionales, lo que incluye no ser discriminados por su nacionalidad, condición de clase, etnia, género, discapacidad o preferencia sexual; que se abran espacios a la crítica cultural en distintos formatos y géneros; que se garantice el acceso mediático a diversos patrimonios culturales; que se satisfagan contenidos de calidad, que sean transmitidos íntegramente y en versión 
original; que los miembros de las audiencias sean considerados copropietarios del patrimonio audiovisual que se va generando; que se permita a las personas organizarse para producir autorepresentaciones individuales o grupales para ser difundidas por los medios; y, servicios técnicos de calidad. Ninguno de los principios anteriores es atendido por la Ley General de Comunicación Social.

Se aduce en el quinto concepto de invalidez que la Ley viola los principios internacionales en materia de publicidad oficial, ${ }^{19}$ así como los señalados en el artículo 134 constitucional. La ley no satisface principios como los siguientes: 1) No es clara ni precisa; 2) No garantiza objetivos legítimos de la publicidad; 3) No contempla criterios claros de distribución de pautas estatales; 4) No regula una planeación adecuada; 5) No hay previsión sobre mecanismos transparentes de contratación; 6) No se establecieron mecanismos de transparencia ni de rendición de cuentas; 7) No existe control externo de la asignación publicitaria; y, 8) No se brinda pluralismo informativo en la publicidad oficial.

Los senadores impugnantes aprecian que debería existir un órgano autónomo, revestido con las facultades necesarias para revisar las propuestas presentadas de propaganda gubernamental cumplan con las reglas que previamente deben establecerse en la ley de la materia, que vele por el cumplimiento de los principios de eficiencia, eficacia, economía, transparencia y honradez.

Se señala, que en la Ley impugnada, no solo no hay reglas claras sino una total discrecionalidad para que la Secretaría de Gobernación y sus equivalentes en los Estados, dispongan libremente de los recursos públicos para favorecer a ciertos medios y castigar a otros. En la Ley hay ausencia de reglas que materialicen los principios internacionales. No hay bases que permitan que la publicidad oficial de certeza a los ciudadanos sobre lo que se debe transmitir en los

19 Principios sobre Regulación de la Publicidad Oficial y Libertad de Expresión. Relatoría Especial para la Libertad de Expresión de la Comisión Interamericana de Derechos Humanos de 7 de marzo de 2011. 
tiempos oficiales y para que el gasto destinado a ello sea erogado de manera transparente y eficaz.

El sexto concepto de invalidez alude a las distintas violaciones al proceso legislativo que invalidan la ley. Con apoyo en lo resuelto en la acción de inconstitucionalidad 52/2006, los senadores sostuvieron que no existió una deliberación incluyente que incorporara a todos los grupos parlamentarios. Las violaciones al proceso parlamentario son trascendentes porque no satisficieron los siguientes parámetros: 1) El procedimiento legislativo no respetó el derecho a la participación de todas las fuerzas políticas con representación parlamentaria, en condiciones de libertad e igualdad; 2) El procedimiento legislativo no culminó con la correcta aplicación de las reglas de votación establecidas; y, 3) Hubo fases del procedimiento parlamentario que no fueron públicas.

En la hipótesis se aprobó por el Pleno del Senado un Acuerdo de la Mesa Directiva del Senado de fecha 24 de abril de 2018 que modificó el proceso legislativo. El punto segundo de ese acuerdo estableció que: "En caso de que las Comisiones Unidas de Gobernación; Radio, Televisión y Cinematografía; y de Estudios Legislativos Primera, no remitan, a más tardar, para el martes 24 de abril de 2018 a la Mesa Directiva el dictamen de proyecto de decreto por el que se expide la Ley General de Comunicación Social, recaído a la minuta enviada por la Cámara de Diputados para su trámite procesal legislativo, la Mesa Directiva acuerda que su Presidente, en la sesión plenaria inmediata siguiente a la fecha mencionada, les retire el proyecto y en sus términos lo presente al Pleno para su discusión y votación”. El citado Acuerdo modificó en su articulado todo el procedimiento previsto en el Reglamento del Senado, pues se trastocó la oportunidad de discusión en comisiones.

El hecho anterior acredita, a juicio de los Senadores, que se produjo un vicio material en la Ley General de Comunicación Social. Resulta claro, desde el punto de vista de los senadores impugnantes, que no existió el debate democrático necesario para el respeto a los 
principios y valores establecidos en la Constitución. Las propuestas de distintos Senadores no fueron tomadas en consideración por las Comisiones encargadas de dictaminar la minuta de la Cámara de Diputados porque las Comisiones no dictaminaron. La Ley General de Comunicación Social aprobada por el Pleno de la Cámara de Senadores el día 25 de abril de 2018, careció de los elementos necesarios para cumplir con el reclamo de la sociedad civil, pues muchas de los argumentos de organizaciones no gubernamentales como FUNDAR o ARTÍCULO 19 fueron totalmente excluidas del debate parlamentario.

Para los Senadores impugnantes fue muy grave que no se tomaran en consideración por las Comisiones del Senado, propuestas como la de la iniciativa \#MediosLibres, que en su momento insistió que se requería lo siguiente: 1) Una Ley General y completa que incluyera a todas las autoridades de los tres órdenes de gobierno, los tres poderes de la Unión, los organismos públicos y cualquier persona que ejerciera o dispusiera de recursos públicos por concepto de publicidad oficial. La ley debía impedir abusos, por ejemplo: a) el contenido propagandístico de la publicidad; b) la discrecionalidad y discriminación en su asignación; c) opacidad en la contratación y el ejercicio de los recursos; d) las deficiencias en la planeación; e) la ausencia de rendición de cuentas y de sanciones; f) la inequidad de la contienda; y g) la utilidad de las campañas. 2) La publicidad debe contener una definición clara de la publicidad oficial y no sólo incluir la publicidad acorada con los medios. También debe ser considerada la publicidad colocada en la vía pública, así como por los intermediarios en redes sociales y plataformas digitales. 3) La publicidad oficial no debe ser entendida como una suerte de subsidio a los medios. El Estado debe apoyar a los medios con otro tipo de subsidios que garanticen la protección del pluralismo y de la diversidad cultural y lingüística; combatir la concentración; y ayudar a la industria mediática. 4) Deben existir mecanismos de 
control externo para vigilar la asignación de contratos y ejercicio de recursos públicos para la publicidad oficial.

La mayoría del Senado ignoró, a juicio de los Senadores impugnantes, todas las recomendaciones que se hicieron llegar a las comisiones dictaminadoras, obvió las iniciativas presentadas en la materia por parte de los legisladores, y rechazó las aportaciones de la sociedad civil.

Las Comisiones del Senado encargadas de dictaminar, cuando se reunieron, por ejemplo, el día 19 y 24 de abril de 2018, desoyeron todo tipo de objeciones y propuestas de modificación a la Minuta enviada por la Cámara de Diputados desde el día 10 de abril de ese año al Senado. Entre las objeciones más importantes estuvo la de algunos Senadores que en Comisiones pidieron reglas claras en la forma en la que se debía asignar el gasto en publicidad oficial y que puntualizaron que era debido que se creara un órgano autónomo que administrara y sancionara la ley de la materia.

La sesión de las Comisiones Unidas del Senado de 19 de abril de 2018 concluyó con una votación en donde dos de las tres comisiones votaron en contra del dictamen -en la sesión extraordinaria de 24 de abril de 2018 la de Gobernación votó a favor, existió empate en la Comisión de Radio, televisión y Cinematografía, y la de Estudios Legislativos Primera votó en contra del dictamen-. Los senadores impugnantes señalan que el Presidente de la Comisión de Gobernación del Senado impuso ante el resultado de las votaciones sus puntos de vista contra toda lógica jurídica e impidió que se destrabaran esos resultados.

En el Pleno del Senado se dispensaron las dos lecturas del dictamen, sin existir entre una dispensa y otra no más de diez minutos de diferencia. Se vulneró el artículo 195 del Reglamento del Senado que determina que cada lectura debe realizarse en sesión consecutiva. No pueden desahogarse las dos lecturas y mucho menos su dispensa en una misma sesión. El dictamen que no fue aprobado en Comisiones se puso de forma antijurídica a consideración del Pleno 
del Senado para su discusión y aprobación, lo que se realizó el día 25 de abril de 2018 .

viI. LA ACCión de inconstitucionalidad de la Comisión Nacional de Derechos Humanos

El Presidente de la Comisión Nacional de los Derechos Humanos presentó acción de inconstitucionalidad en contra de la totalidad de la Ley General de Comunicación Social y respecto a los artículos 4 fracción VI en la porción normativa que dice: "Son los que pueden ser captados simultáneamente por una gran cantidad de individuos", 5, último párrafo, 20, 27, 29, segundo párrafo, 35, 37, 45 y segundo transitorio de la Ley General de Comunicación Social.

Se estiman violados los artículos 1,6,7, 14, 16 y 134 de la Constitución; los artículos 1, 2, 9, 13 y 4 de la Convención Americana sobre Derechos Humanos; así como los artículos 3 y 19 del Pacto Internacional de Derechos Civiles y Políticos. Los derechos humanos infringidos según la demanda son: la libertad de expresión, el acceso plural a la información, derecho a la igualdad y no discriminación, derecho a la seguridad jurídica, derecho de acceso a la justicia, principio de legalidad y principio de reserva de ley.

En sus conceptos de invalidez la Comisión Nacional de Derechos Humanos estima que la ley no contiene reglas claras y transparentes sobre la asignación del gasto en comunicación social. La ley a juicio de la Comisión no cumple con los parámetros previstos armónicamente en los párrafos primero, octavo y noveno del artículo 134 constitucional ni con lo establecido en el artículo tercero transitorio del Decreto de reforma constitucional de 10 de febrero de 2014 ni con las consideraciones de la Suprema Corte de Justicia al resolver el amparo en revisión 1359/2015.

La Comisión Nacional de Derechos Humanos había señalado que la publicidad oficial, a diferencia de la publicidad convencional, no tiene como finalidad promover productos y servicios con un fin 
comercial, su propósito es la concientización de la ciudadanía sobre temas de interés común, es un canal entre el gobierno y la sociedad para informarla, a fin de que ésta pueda participar activamente en la toma de decisiones y ejercer plenamente sus derechos.

En cuanto hace a la publicidad oficial, dice la CNDH, el legislador debe, garantizar a los ciudadanos que los recursos de los que disponga serán destinados a los fines para los cuales hayan sido recaudados, que se gasten de la manera más eficiente y se logren resultados tangibles para la población, que se rindan cuentas oportunamente a los habitantes sobre su aplicación y asegurar el carácter institucional que debe animar a dicha comunicación y los fines informativos, educativos o de orientación social que debe perseguir.

En este sentido, la Ley debe ser plenamente clara y debe impedir decisiones discrecionales en manos de los funcionarios, tal como ha precisado la Comisión Interamericana de Derechos Humanos al emitir los "Principios sobre la Regulación de Publicidad Oficial en el Sistema Interamericano de Protección de los Derechos Humanos", ${ }^{20}$ los que constituyen las bases mínimas para la regulación en la materia.

Estos principios son los siguientes:

1. Establecimiento de leyes especiales, claras y precisas, que exige satisfacer los siguientes estándares:

a) Los Estados están obligados a adoptar reglas legales específicas sobre publicidad oficial en cada uno de los niveles de gobierno. La carencia de un marco legal específico y adecuado para la definición de los objetivos, la asignación, contratación y control de la pauta estatal permite una utilización arbitraria de estos recursos en detrimento de la libertad de expresión.

20 Comisión Interamericana de Derechos Humanos, "Principios sobre la Regulación de Publicidad Oficial en el Sistema Interamericano de Protección de los Derechos Humanos", 2011 , párrafo 33. 
b) Los Estados tienen, el deber de adoptar lineamientos legales claros y concretos como parte integral de su deber de garantizar el ejercicio de la libertad de expresión.

c) La norma debe contener una adecuada regulación de los mecanismos de producción y asignación de la pauta estatal con el objeto de limitar la excesiva discrecionalidad que permite la violación de los derechos a las libertades de pensamiento y expresión.

d) Las buenas prácticas, los mecanismos informales, las regulaciones defectuosas o dispersas no son suficientes para evitar las violaciones a la libertad de expresión.

e) Se debe definir a la publicidad oficial de manera sencilla y abarcadora, por ejemplo, estableciendo que la publicidad estatal es toda comunicación, anuncio o espacio solventado con fondos públicos, en cualquier medio de comunicación y en cualquier soporte.

f) Las diferentes etapas vinculadas a la producción, contratación, distribución y control del avisaje del sector público y privado costeado con fondos públicos, deben encontrarse comprendidas en esta regulación.

g) Las reglas legales específicas de publicidad oficial deben incorporar los principios de interés público, transparencia, rendición de cuentas, no discriminación, eficiencia y buen uso de los fondos públicos.

h) El marco legal debe incluir una descripción exhaustiva de su ámbito de aplicación.

i) La regulación debe incluir sanciones apropiadas para la violación de las disposiciones.

2. Objetivos legítimos de la publicidad oficial que están vinculados con la utilidad pública y no constituir propagan- 
da encubierta con gobernantes o de sus intereses, ni ser utilizada para la estigmatización de sectores opositores o críticos del gobierno.

3. Criterios de distribución de la pauta estatal. Se deben establecer procedimientos que reduzcan la discrecionalidad. Por eso, los criterios deben estar preestablecidos, ser claros, transparentes y objetivos.

4. Planificación adecuada. Las instancias del Estado deben realizar una adecuada planeación de la publicidad estatal para no propiciar un ejercicio abusivo de los fondos públicos que se destinan a ella.

5. Mecanismos de contratación. Los procedimientos deben ser abiertos. Se deben privilegiar las licitaciones públicas. Las modalidades diversas de contratación deben estar justificadas y ser excepcionales.

6. Transparencia y acceso a la información. Todos los datos y hechos vinculados a las decisiones adoptadas en materia de publicidad oficial deben ser completamente públicos.

7. Control externo de la asignación publicitaria. Un órgano autónomo debe encargarse de monitorear la asignación de publicidad oficial, incluyendo las auditorías sobre los gastos.

8. Pluralismo informativo y publicidad oficial. La publicidad oficial no debe entenderse como un mecanismo de ayuda indirecta o subsidio a los medios.

La Ley General de Comunicación Social no cumple con los anteriores principios, ni con los convencionales ni con los constitucionales, por las siguientes razones:

1. Delega en normas infralegales el establecimiento de criterios de selección del medio de comunicación para la asignación de la pauta de publicidad oficial. 
2. La ley no contempla criterios objetivos, claros y transparentes en los que las dependencias puedan fundar y motivar la elección de contratación de medios publicitarios.

3. La Ley favorece la discrecionalidad en el otorgamiento de la publicidad oficial. No se establecen, por ejemplo, topes da gasto en la materia ni topes de asignación para cada medio y cada campaña.

4. La organización del Padrón Nacional de Medios de Comunicación Social no se prevé exhaustivamente en la Ley. Se delega esa organización a normas administrativas, lo que abre la puerta para la asignación arbitraria y discriminatoria de la publicidad oficial que permitirá presionar, castigar, premiar y privilegiar a ciertos medios y comunicadores.

5. La ley por lo mismo no garantiza condiciones de igualdad de trato entre los medios.

6. Se incumple el mandato del último párrafo del artículo 134 constitucional que señala que la comunicación social se debe regular por ley.

7. La ley no regula con suficiencia las responsabilidades ni las sanciones. En particular la ley no establece claramente las sanciones de índole administrativa, civil o penal que serán aplicables. Los superiores jerárquicos al tenor del artículo 45 de la Ley son los que decidirán si proceden al respecto por la violación a la ley.

8. La Ley en su artículo 5, último párrafo establece en contra de la Constitución que la Secretaría Administradora deberá contemplar en los lineamientos que emita, los criterios de selección del medio de comunicación correspondiente.

9. El artículo 20 de la Ley dispone que las Secretarías Administradoras emitirán anualmente los lineamientos que contengan las reglas relativas a la difusión de las campañas 
de carácter industrial, comercial, mercantil y de promoción de publicidad que promuevan o publiciten la venta de productos o servicios que generan algún ingreso para el Estado.

10. El artículo 27 de la Ley alude a lineamientos para las estrategias, programas y campañas de comunicación social y normas administrativas en materia presupuestaria.

11. Los artículos 35, 37 y el segundo transitorio de la ley habilitan a la Secretaría de Gobernación para establecer lineamientos que organicen el Padrón Nacional de Medios de Comunicación.

12. La referencia indiscriminada que la Ley impugnada realiza respecto a la creación de lineamientos y la ausencia de parámetros claros en la misma a los que deberán ceñirse los sujetos obligados genera una afectación a la seguridad jurídica, tanto para los entes públicos como para los medios y las personas, dada las dimensiones individual y social de la libertad de expresión.

La Comisión Nacional de Derechos Humanos recuerda el Informe de 2017 que los Relatores Especiales para la Libertad de Expresión de la ONU como de la Comisión Interamericana de Derechos Humanos emitieron respecto a México, en donde en el párrafo 55 del mismo señalaron que:

En una decisión de suma relevancia, la Suprema Corte recientemente ordenó al Congreso desarrollar regulaciones para la práctica de publicidad oficial. Según algunos informes, el gobierno federal ha gastado más allá de 34 mil millones de pesos en los últimos cuatro años en dicha publicidad. Las reglas de esa publicidad son obscuras, que llevan a muchos a concluir, con evidencia sustancial, que los actores de gobierno utilizan los fondos de publicidad para dar forma y distorsionar la cobertura de medios y difuminar las líneas entre historias de noticias verificables y propaganda o incidencia 
política. Ese gasto también sirve como subsidio para mantener los medios heredados a flote para el detrimento de fuentes alternativas de información. Acogemos la decisión de la Suprema Corte e instamos al Congreso a no sólo adoptar reglas claras y públicas que rigen la publicidad y aseguran reportajes frecuentes y específicos, sino que también desarrollan un plan para limitar de forma progresiva esos gastos en conjunto, en consulta con la sociedad civil y los expertos pertinentes. Manifestamos nuestra disponibilidad para proporcionar asesoría técnica al Congreso en relación con las normas internacionales sobre publicidad oficial en los meses venideros antes de la adopción de esa ley. ${ }^{21}$

En este sentido, la ley impugnada carece de reglas claras, lo que se traducirá en discrecionalidad y arbitrariedad del Estado. El gasto en publicidad oficial se empleará como mecanismo de censura indirecta. Se castigará a los medios críticos al gobierno con el uso discrecional y arbitrario de los recursos públicos para la publicidad oficial.

La deficiencia normativa no es menor porque tiene un efecto disuasivo en el ejercicio de la libertad de expresión. La arbitrariedad que se deriva de la deficiente regulación pudiera llevar a determinados medios a adoptar posiciones deferentes con el gobierno con la finalidad de no verse afectados con perder recursos asignados a la difusión de la publicidad oficial.

\section{vili. Conclusiones}

Primera. La Ley General de Comunicación Social va más allá de lo previsto en el párrafo octavo del artículo 134 constitucional por-

21 Oficina del Alto Comisionado de la Organización de las Naciones Unidas y la Relatoría Especial para la Libertad de Expresión de la Comisión Interamericana de Derechos Humanos, "Observaciones preliminares del Relator Especial de la ONU sobre la libertad de expresión y el Relator Especial sobre la libertad de expresión de la GIDH después de su visita conjunta en México, 27 de noviembre-4 de diciembre 2017", México 2017, párrafo 55. 
que el artículo 4 fracción I permite difundir logros del gobierno, lo que rompe con la equidad que debe existir en democracia entre el gobierno y la oposición. La norma constitucional constriñe la publicidad del gobierno a las siguientes características: a) Tener carácter institucional; b) Satisfacer fines informativos, educativos o de orientación social; y, c) No contener nombres, imágenes, voces o símbolos que impliquen promoción personalizada. Es decir, la publicidad gubernamental no tiene por fin promover los logros del gobierno. Debe ser propaganda neutral.

Segunda. La neutralidad de los medios respecto al gobierno y su propaganda está reconocida en todas las democracias. Ejemplo el artículo 66 de la ley Orgánica 2/2011 de España, de 28 de enero de ese año. La publicidad gubernamental debe ser neutral. No es para difundir logros.

Tercera. El último párrafo del artículo 134 de la Constitución establece el principio de reserva de ley en materia de publicidad gubernamental. Sólo por ley puede regularse la materia y no a través de normas administrativas. En la ley, en distintos preceptos, se reenvía a lineamientos de la Secretaría de Gobernación y a otras normas administrativas generales y abstractas.

Cuarta. La ley general de comunicación social no toca ni con el pétalo de una rosa a los medios electrónicos de nuestro país -TV y radio-. Aunque se prevé que la publicidad gubernamental se difundirá en tiempos oficiales -fiscales y del Estado- la publicidad del Estado será fundamentalmente contratada con los medios de radiodifusión privados. Los tiempos oficiales para transmitir la publicidad gubernamental tienen un rol secundario en la ley.

Quinta. Para futuras reformas en materia electoral en beneficio de los medios de radiodifusión, dolosamente el párrafo segundo del artículo 6 de la ley, mezcla y confunde la libertad de expresión con la libertad de contratación. No son la misma libertad, son libertades distintas. 
Sexta. El artículo 14 de la ley que se refiere a los informes anuales de los funcionarios es totalmente inconstitucional. Transgrede la letra del párrafo octavo del artículo 134 de la Constitución que dice que la publicidad gubernamental no deberá..." contener nombres, imágenes, voces o símbolos que impliquen promoción personalizada"

Séptima. El artículo 17 de la ley permite que la Secretaría de Gobernación, violando el principio de división de poderes -artículo 49- y la autonomía de los órganos constitucionales autónomos, reasigne los tiempos fiscales que corresponden a los poderes y a los órganos autónomos.

Octava. No existe tope para el gasto en la publicidad gubernamental. Podrá seguir siendo excesivo.

Novena. En materia electoral no se da un paso adelante. Sólo se prohíbe la publicidad gubernamental durante las campañas -artículo 21 - y no durante todo el proceso electoral. Ello violenta el principio de equidad electoral previsto en el artículo 41 constitucional.

Décima. El artículo 21 de la ley violenta la autonomía constitucional del INE reconocida en el artículo 41 constitucional, pues la autoridad electoral deja de ser la autoridad máxima durante los procesos electorales. La Secretaría de Gobernación podrá autorizar publicidad gubernamental más allá de lo que determine el INE durante el proceso electoral.

Décima primera. El control de la administración de la publicidad gubernamental: el diseño, gasto, supervisión y evaluación de la publicidad del Estado mexicano corresponde fundamentalmente al Poder Ejecutivo. Poder inmenso que se ejercerá con criterios políticos.

Décima segunda. La ley no garantiza el principio de equidad entre los medios para el reparto de los recursos contratados para la publicidad gubernamental. La ley favorece el reparto discrecional y arbitrario de los recursos públicos para ella. 
Décima tercera. El artículo 31 de la ley no determina que la publicidad o mensajes extraordinarios tengan que justificarse por una instancia externa. Nuevamente la ley favorece la discrecionalidad y arbitrariedad

Décima cuarta. No se prevén mecanismos de evaluación ciudadana sobre el gasto en publicidad gubernamental.

Décima quinta. El control sobre el gasto en publicidad gubernamental es a posteriori. No existe control previo ni concomitante sobre la publicidad gubernamental.

Décima sexta. El apartado de responsabilidades de la ley es profundamente débil y ambiguo. Las conductas materia de sanción administrativa son indeterminadas. Cualquier amparó que promueva algún sancionado será concedido. No existen sanciones severas a quién viola la ley. Ésta no determina que el responsable por las infracciones a la ley será el titular de la dependencia, entidad, poder u órgano.

Décima séptima. La ley no prevé tipos penales en materia de publicidad gubernamental.

Décima octava. La ley no modifica el status quo en la materia. Lo legaliza, lo mantiene.

Décima novena. Lo anterior significa que se mantendrá jurídicamente la dictadura mediática porque el respeto a los principios de pluralismo político y social, de equidad, así como a la igualdad, proporcionalidad y neutralidad informativa, campean en la ley por su ausencia.

Vigésima. En contra de los estándares internacionales, los recursos públicos para la publicidad oficial seguirán empleándose en México, como una forma de subsidio a favor de los medios de comunicación.

Vigésima primera. No se prohíben las transferencias, adecuaciones y traspasos presupuestales en la materia. Lo aprobado para publicidad oficial en el legislativo puede ser modificado e incremen- 
tado por el ejecutivo en contra de lo previsto en el artículo 126 de la Constitución.

Vigésima segunda. Por los fuertes componentes discrecionales derivados de las competencias que la ley asigna a favor de la Secretaría de Gobernación, la censura indirecta seguirá siendo una realidad en nuestro país.

\section{iX. Fuentes}

Apreza Salgado, Socorro, "La regulación de la publicidad oficial y las medidas anticoncentración de medios de comunicación: otro nudo gordiano del pluralismo informativo en México", Revista de la Facultad de Derecho de México, México, vol. 60, número 254, 2010.

Baños, Marco Antonio y Carriedo, Luis Miguel, "Distorsiones de la propaganda política”, Revista Justicia Electoral, México, Vol. 1, número 5, 2010.

Comisión Interamericana de Derechos Humanos, "Principios sobre la Regulación de Publicidad Oficial en el Sistema Interamericano de Protección de los Derechos Humanos", 7 de marzo de 2011.

Gorral Jurado, Javier, "Propaganda gubernamental y artículo 134 constitucional" en Ackerman Rose, John Mill (coordinador), Elecciones 2012: en busca de la equidad y legalidad, México, UNAM-Instituto de Investigaciones Jurídicas de la UNAM y Senado de la República, 2011.

Desiree Salgado, Eneida y Seraphim Makarausky, Camila, "Propaganda electoral, publicidad gubernamental y encuestas electorales: un análisis del modelo mexicano desde una mirada brasileña”, Sufragio. Revista Especializada en Derecho Electoral, México, número 12, 2014 .

Esteinou Madrid, Javier y Alva de la Selva, Alma Rosa (coordinadores), La "Ley Televisa" y la lucha por el poder en México, México, Universidad Autónoma Metropolitana, 2009. 
Faúndez Ledesma, Héctor, Los límites de la libertad de expresión, México, UNAM, 2004.

García Mahamut, Rosario y Rallo Lombarte, Artemi, "Neutralidad y pluralismo de los medios de comunicación en las campañas electorales: la reforma de la LOREG de 201 1", Revista Española de Derecho Constitucional, Madrid, número 98, mayo-agosto de 2013.

Gilas, Karolina M., Libertad de expresión en el ámbito electoral en México (a la luz de los estándares internacionales), México, Tirant Lo Blanch, 2016.

Guevara Montemayor, Alberto, "Suspensión de propaganda gubernamental y derecho de acceso a la información pública: hacia un punto de equilibrio en México", en Revista Estudios en Derecho a la Información, México, número 1, enero-junio de 2016.

López Guerra, Luis, y otros, Derecho constitucional. El ordenamiento constitucional. Derechos y deberes de los ciudadanos, Volumen I, Valencia, 2018.

Magistrados de la Sala Superior del TEPJF, Propaganda gubernamental. Excepciones durante un periodo de campaña. Expediente SUP-RAP-54/2012 y acumulados, México, Tribunal Electoral del Poder Judicial de la Federación, 2014.

Marván Laborde, María, "La propaganda gubernamental: un exceso", Revista Hechos y Derechos del Instituto de Investigaciones Jurídicas de la UNAM, México, número 39, mayo-junio, 2017, disponible en: <https://bit.ly/2RDOoXm>.

Montabes Pereira, Juan, La prensa del Estado durante la transición política española, Madrid, siglo XXI editores y Centro de Investigaciones Sociológicas, 1989.

Oficina del Alto Comisionado de la Organización de las Naciones Unidas y la Relatoría Especial para la Libertad de Expresión de la Comisión Interamericana de Derechos Humanos, "Observaciones preliminares del Relator Especial de la ONU sobre la libertad de expresión y el Relator Especial sobre la libertad de expresión de la CIDH después de su visita conjunta en México, 27 de noviembre-4 de diciembre 2017", México 2017. 
Pérez de la Fuente, Óscar, Libertad de expresión y discurso político, México, Tirant Lo Blanch, 2015.

Resolución del amparo en revisión 1359/ 2015 de 15 de noviembre de 2017, Primera Sala. Suprema Corte de Justicia de la Nación. Ministro ponente: Arturo Zaldívar Lelo de la Larrea.

Salazar Rebolledo, María Grisel, "Resistiendo el clientelismo. Publicidad gubernamental y subsistencia de la prensa crítica", Colombia Internacional, número 95, Colombia, 2018, disponible en: <https://bit.ly/2TYcicr>.

SARTORI, Giovanni, ¿Qué es la democracia?, Madrid, Taurus, 2007.

Stiglitz, Joseph, El precio de la desigualdad. El 1\% de la población tiene lo que el 99\% necesita, traducción de Alejandro Pradera, México, Taurus-Prisa Ediciones, 2012.

Stuart Mill, John, Sobre la libertad, Madrid, Alianza editorial, 2017.

Tocoueville, Alexis de, La democracia en América, México, Fondo de Cultura Económica, 1957.

Trejo Delarbre, Raúl, "Información y medios en la Constitución de la Ciudad de México", en Configuraciones. Aportes al debate constituyente de Ciudad de México, Revisa de la Fundación Pereyra y del Instituto de estudios para la transición democrática, número, 41, mayo-agosto de 2016.

Villafranco Robles, Citlali, "Campañas electorales en el límite de la ley. El caso de la propaganda gubernamental del Partido Verde Ecologista de México", Revista Justicia Electoral, Vol. 1, número 17, enero-junio, 2016.

Villamil, Jenaro, "Derecho a la información, la otra gran desigualdad en México", en Florescano, Enrique y Cossío, Ramón D. (coordinadores), Hacia una nación de ciudadanos, México, Fondo de Cultura Económica, 2014.

Villanueva, Ernesto, Régimen constitucional de las libertades de expresión e información en los países del mundo, México, editorial Fragua, 1997.

Virginia v. Black, 538 US 343, 367 (2003); New York v. Ferber, 458 US 747, 769, n. 24 (1982). 